\title{
Nd isotopic composition in the northern Indian Ocean from late Quaternary to the present
}

\author{
ZhaOJIE YU ${ }^{1}$, ChRISTOPHE COLIN ${ }^{2}$, FRANCK \\ BASSINOT $^{3}$, SHIMING WAN ${ }^{1}$ \\ 1. Institute of Oceanology, Chinese Academy of Sciences, Qingdao 266071, China \\ 2. GEOPS, UMR 8148, CNRS-Université de Paris-Sud, Université Paris-Saclay, France \\ 3. LSCE/IPSL, CEA-CNRS-UVSQ, Université Paris-Saclay, Gif-sur-Yvette, France
}

Constraining the dissolved neodymium $(\mathrm{Nd})$ cycle in the ocean is paramount for using $\mathrm{Nd}$ isotopic composition ( $\varepsilon \mathrm{Nd})$ as a tracer to reconstruct deep-sea paleocirculations or continental weathering on different time scales. Dissolved $\varepsilon_{\mathrm{Nd}}$ has been measured in seawater samples from six hydrological stations collected along $\sim 89^{\circ} \mathrm{E}$ North-South transect in the Bay of Bengal $(\mathrm{BoB})$ in order to assess the impact of seasonal freshwater and sediment discharges from the continental river system. Seawater samples collected in this study during June 2012 reveal more radiogenic $\varepsilon \mathrm{Nd}$ (a difference of $\sim 2$ Epsilon units for the upper $2000 \mathrm{~m}$, and $\sim 0.5$ Epsilon unit below 2000 $\mathrm{m})$ and $\sim 3-8 \mathrm{pmol} / \mathrm{kg}$ lower $\mathrm{Nd}$ concentrations than the reported values of nearby seawater samples collected in November 2008. These observations are most plausible explained by a seasonal variation in dissolved $\mathrm{Nd}$ concentrations and $\varepsilon \mathrm{Nd}$ in the $\mathrm{BoB}$, induced by seasonal variations in the freshwater and sediment discharges from the G-B river system. Based on the modern seawater Nd results, $\varepsilon_{\mathrm{Nd}}$ of mixed planktonic foraminifera from core MD77-176 from an intermediate depth in the Northern Indian Ocean are selected to reconstruct the past evolution of intermediate water during deglaciation. The $\varepsilon_{\mathrm{Nd}}$ record in the Northern Indian Ocean displays two pulse-like shifts towards more radiogenic Southern Ocean values during the deglaciation, and these shifts coincide with excursions in $\Delta^{14} \mathrm{C}$ and $\varepsilon \mathrm{Nd}$ records in the Pacific and Atlantic Oceans. These results suggest invasion of AAIW into the Northern Hemisphere oceans associated with enhanced Southern Ocean ventilation during deglaciation. Our new $\varepsilon_{\mathrm{Nd}}$ record strongly supports the close linkage of AAIW propagation and atmospheric $\mathrm{CO}_{2}$ rise through Southern Ocean ventilation during deglaciation.

Key words: $\mathrm{Nd}$ isotopic composition; deglaciation; atmospheric $\mathrm{CO}_{2}$; Northern Indian Ocean. 